\title{
Mind the gap: Patterns of red blood cell product usage in South Africa, 2014 - 2019
}

\author{
L Bolton, ${ }^{1}$ BSc, PhD; K van den Berg, ${ }^{2,3}$ MB ChB, MMedSci (Transfus Med); R Swanevelder, ${ }^{2}$ BCom, BSc Hons, MS; J R C Pulliam, ${ }^{1}$ PhD \\ ${ }^{1}$ South African DSI-NRF Centre of Excellence in Epidemiological Modelling and Analysis (SACEMA), Stellenbosch University, Stellenbosch, \\ South Africa \\ ${ }^{2}$ Translational Research, Medical Division, South African National Blood Service, Roodepoort, South Africa \\ ${ }^{3}$ Division of Clinical Haematology, Department of Medicine, Faculty of Health Sciences, University of Cape Town, South Africa
}

Corresponding author: L Bolton (lbolton@sun.ac.za)

Background. A key component of any successful healthcare system is the availability of sufficient, safe blood products delivered in an equitable manner. South Africa (SA) has a two-tiered healthcare system with public and privately funded sectors. Blood utilisation data for both sectors are lacking. Evaluation of blood utilisation patterns in each healthcare sector will enable implementation of systems to bring about more equality.

Objectives. To conduct a critical evaluation of red blood cell (RBC) product utilisation patterns at the South African National Blood Service (SANBS).

Methods. Operationally collected data from RBC requests submitted to SANBS blood banks for the period 1 January 2014 - 31 March 2019 were used to determine temporal RBC product utilisation patterns by healthcare sector. Demographic patterns were determined, and per capita RBC utilisation trends calculated.

Results. Of the 2356441 transfusion events, 65.9\% occurred in the public and $34.1 \%$ in the private sector. Public sector patients were younger (median (interquartile range (IQR)) 33 (22 - 49) years) than in the private sector (median (IQR) 54 (37 - 68) years), and mainly female in both sectors (66.2\% in the public sector and 53.4\% in the private sector). Between 2014 and 2018 , per capita RBC utilisation decreased from 11.9 to $11.0 / 1000$ population in the public sector, but increased from 34.8 to $38.2 / 1000$ population in the private sector. Conclusions. We confirmed distinctly different RBC utilisation patterns between the healthcare sectors in SA. Possible drivers for these differences may be healthcare access, differing patient populations and prescriber habits. Better understanding of these drivers may help inform equitable public health policy.

S Afr Med J 2021;111(10):985-990. https://doi.org/10.7196/SAMJ.2021.v111i10.15658

In pursuit of universal health coverage, low- and middle-income countries (LMICs) have been undergoing restructuring of their healthcare funding mechanisms. ${ }^{[1]}$ However, healthcare benefits in sub-Saharan Africa have still been found to be 'pro-rich. ${ }^{[1,2]}$ The South African (SA) two-tiered healthcare system stands as an example of the challenge facing other LMICs with similarly structured healthcare systems, namely to dismantle separate health financing mechanisms applied to different sections of the population, and transition to universal coverage. ${ }^{[2]}$

The SA healthcare system comprises two distinct and contrasting systems, namely the public and private health sectors. ${ }^{[3,4]}$ The public sector is state funded $\mathrm{d}^{[5]}$ and accessed predominantly by those without private coverage; the majority of this population therefore falls within the lower income categories, ${ }^{[6]}$ which also face the greatest health challenges ${ }^{[7]}$ In contrast, the private sector is accessed predominantly by the employed population with private cover, affording them admittance to a better-resourced care setting. ${ }^{[3]}$ The privately funded population comprised only $17.5 \%$ of the total population in $2015,{ }^{[8]}$ but just over half of the $8.5 \%$ of the gross domestic product that was spent on healthcare in SA was spent in the private sector. ${ }^{[9]}$ The impact of this inequality in funding between the two sectors probably explains the significant difference in the rating of the two services. The SA private sector is said to be on par with developed countries such as Switzerland and Sweden, attaining sixth-highest position out of 48 countries under consideration, with the public sector rated in the eighth-lowest position (cited in Burger and Christian ${ }^{[3]}$ ). The inequality between the sectors is further evident in the division of the health workforce, with the public sector suffering from a severe staff shortage. ${ }^{[10]}$ The SA government is taking steps towards universal health coverage, implementing a national health insurance (NHI) programme and initiating a health system that is to be uniform across the country. ${ }^{[11]}$ This shift will have ripple effects on, among others, the providers of blood products, as both service delivery and cost recovery models are likely to be affected.

The availability of sufficient, safe blood and blood products is a key component of an effective healthcare system. In SA, the only blood establishments licensed by the National Department of Health are the South African National Blood Service (SANBS) and the Western Cape Blood Service (WCBS). In 2018, the SA population was estimated at 57.73 million individuals, spread throughout nine provinces. ${ }^{[12]}$ The population of Western Cape Province, comprising $11.5 \%$ of the entire SA population in $2018,{ }^{[12]}$ is serviced by the WCBS ${ }^{[13]}$ Comparatively, the SANBS through its seven operational zones supplies the blood product needs of the rest of the country. ${ }^{[14]}$ Both the SANBS and the WCBS impartially provide required blood products and services to both healthcare sectors. The majority of the blood banks are located in close proximity to public sector facilities, resulting in easier access to blood products in the public sector, yet anecdotal reports suggest significantly higher utilisation of blood products in the private sector compared with the public 
sector. Considering the sparse existing evidence in the context of the two-tiered healthcare system, quantifying and interrogating blood utilisation patterns is necessary to help inform policy to ensure national blood security, and lay the groundwork for evaluation of adherence to clinical guidelines for the use of blood products, ultimately improving the outcomes for the patient. ${ }^{[15]}$

\section{Objectives}

To determine trends in red blood cell (RBC) product utilisation for recipients serviced by the SANBS between the two healthcare sectors, as well as temporal sector-specific patterns of utilisation. This will provide pivotal information regarding the differing patient characteristics and provider prescribing habits in the sectors, highlighting disparities and generating hypotheses regarding possible drivers of such disparities. An understanding of what drives the differences in blood utilisation patterns in this two-tiered healthcare system will go a long way to providing recommendations to bring about more equality between the sectors, thereby generating a more sustainable blood supply model for universal health coverage.

\section{Methods \\ Study setting}

The SANBS is the larger of the two blood transfusion services in SA and provides a vein-to-vein service, supplying blood and blood products exclusively collected from voluntary non-remunerated donors to both the public and the private sectors on a cost recovery basis. The SANBS operates in eight of the country's nine provinces, supplying blood through 83 blood banks of various sizes to $~ 340$ public and 250 private hospitals. Blood is also distributed to rural hospitals through a network of emergency blood fridges placed in strategic wards in these hospitals. Blood issued through these fridges is referred to as ward stock. Blood is ordered through the submission of a requisition form, signed by a doctor. Where required, a crossmatch sample is dispatched to the local blood bank, where the crossmatch sample is used to perform blood grouping and compatibility testing prior to the issuing of compatible units to the patient. As per legal requirements, all issued products are fully traceable from donor to recipient.

\section{Data collection}

The operational data collected for each requisition by the SANBS included patient-specific information such as age, sex and certain clinical information, as well as hospital identification and patient type (patient registration as antenatal, ward stock, and public or private patient). The dataset also included product-specific information such as type of product(s), number of product units ordered, cancelled and issued, and if units were cancelled, the reason for cancellation. These data were captured on the MEDITECH blood bank electronic system by blood bank technicians at the time of request and issue and extracted from the SANBS data warehouse database built on the MEDITECH system. De-identified data were used for this analysis.

\section{Study design}

We conducted a retrospective analysis of operational data collected by the SANBS between 1 January 2014 and 31 March 2019. From the original SANBS dataset, the subset used in this investigation included all $\mathrm{RBC}$ product requests for both public and private patients submitted to SANBS blood banks during the study period. Patients may have multiple requests during a hospital stay if additional blood products are required $>72$ hours after a specimen for blood typing was collected. Each product requisition was uniquely identified by a requisition number and represents a transfusion event. Individual product requisitions could be associated with multiple RBC units. For the sector-specific analyses, demographic information associated with the transfusion events was analysed for overall trends in age and gender, whereas the number of issued units was analysed for temporal and overall trends in utilisation, all stratified between the public and private healthcare sectors. Owing to lack of information on medical aid coverage, antenatal patient registrations and ward stock requisitions were excluded from the sector-specific analyses.

\section{Data analysis}

The data were analysed in RStudio version 1.1.463 (RStudio, USA), ${ }^{[16]}$ running $\mathrm{R}$ statistical software version 3.6.2. ${ }^{[17]}$ The demographic information relating to the transfusion events was analysed using descriptive statistics, and gender distributions were ascertained and compared. Visualisation of the relationship between gender and age for the transfusion events, stratified by healthcare sector, was used to illustrate overall demographic trends. Utilisation trends were analysed via the number of RBC product units issued per 1000 of the respective SA healthcare sector population. More specifically, the total number of RBC units issued by the SANBS to a particular healthcare sector population over a specified period was determined and divided by the respective population size over the same period. The latter was then represented per 1000 of the respective healthcare sector population. The Western Cape population estimates were excluded because utilisation values did not include this province.

The original SANBS dataset was found to contain RBC product requisitions with discrepancies between the number of ordered and issued counts. These issued counts were re-assigned as missing values and multiple imputation was employed using the mice package ${ }^{[18]}$ in $\mathrm{R}$ statistical software ${ }^{[17]}$ under the assumption of missing at random $^{[18]}$ (supplementary material, available at http://samj.org.za/ public/sup/15658.pdf). It was further assumed that the requisitions with cancelled counts exceeding their respective ordered counts were erroneous, and the identified discrepant cancelled count was replaced with the number of units of the blood product ordered. The dataset used during imputation only contained the variables theorised to be possible predictors of the imputed variable (the issued count). As a starting point, variables were selected from the original dataset on the basis of either being associated with the calculation of the issued count or possibly able to explain variability between the counts. ${ }^{[19]}$ The quickpred() function was then applied within the mice package ${ }^{[18]}$ on this refined dataset, which selected the variables that were the most probable predictors for the missing values. Issued counts missing in the original dataset were then replaced with their imputed values to generate the dataset for analysis.

\section{Data considerations}

Firstly, the manual capturing of operational information opens the data to capturing errors, which could influence the level of accuracy of the data; however, the legal requirement for donor-to-recipient traceability within the system and the large sample size should limit the impact of such capturing errors. Secondly, the difference between the number of RBC units ordered and cancelled should equate to the number of RBC units issued. However, between 2014 and 2018 there was a steady increase in the percentage of $\mathrm{RBC}$ requisitions (from the original SANBS dataset) with discrepancies between the counts (12 033 or $2.75 \% \mathrm{RBC}$ requisitions in 2014 to 21525 or $4.63 \% \mathrm{RBC}$ requisitions in 2018). Overall, 87615 or $3.64 \% \mathrm{RBC}$ requisitions over the entire study period were discrepant, of which 84478 or $96.42 \%$ RBC requisitions had no recorded cancellations. The majority (66 567 or $75.98 \%$ RBC requisitions) reflected only a 
1-unit difference. Although a noteworthy limitation, the observed discrepancies therefore do not invalidate the study outcomes. The data used in this study are operational and employed to actively manage inventory. Thirdly, the imputation used to generate realistic estimates for missing issued counts is unlikely to have a considerable impact on the accuracy of the results, given the low number of issued counts requiring imputation ( 377 or $0.015 \%$ RBC product issued counts). Fourthly, the Western Cape utilisation figures were not included in this investigation. This province may reveal differing utilisation trends compared with the reported results. Finally, certain clinical and demographic data, such as date of birth, were often not available, although recipient age was generally available.

\section{Ethical considerations and data sharing}

Ethical approval was obtained from the human research ethics committees (HRECs) of SANBS (ref. no. 2017/7) and Stellenbosch University (ref. no. N18/10/128_RECIP_SANBS_2017/7).

Supplementary material containing further details on data imputation is available online (http://samj.org.za/public/sup/15658. pdf). De-identified data can be shared subject to SANBS HREC approval of data request and/or study protocol approval. Upon non-disclosure agreement between the SANBS and the requesting individual or organisation, the data fields, data dictionary and analysis code will be made available as per approved request.

\section{Results}

\section{Transfusion events}

We analysed 2356441 public and private recipient RBC transfusion events (Table 1). Of the transfusion events analysed, 1553159 (65.9\%) occurred in the public sector and $803282(34.1 \%)$ in the private sector. Recipients in the public sector were younger (median (interquartile range (IQR)) $33(22$ - 49) years) than in the private sector (median (IQR) $54(37$ - 68) years), and predominantly female (66.2\% v. 53.4\% in the private sector).

Fig. 1 depicts the comparative healthcare sector distribution for RBC transfusion events by gender and age over the study period. There was a 1:2 ratio in the transfusion events for males $v$. females in the public sector, compared with a 1:1 ratio in the private sector. Recipients in the public sector were younger, with the most transfusion events occurring in the 0 - 4- and 20 - 39-year age groups, the former being predominantly male and the latter predominantly female. Recipients in the private sector were older, with a trend towards increasing events with increasing age. The most transfusion events occurred in men in the 55 - 59-year age group and in women aged $\geq 80$ years.

\section{Trends in RBC utilisation between the public and private healthcare sectors}

The public sector had a larger proportion of requisitions with no units issued ( $10.6 \%$ v. $6.0 \%)$ or only one unit issued $(36.0 \%$ v. $26.8 \%)$ compared with the private sector. The private sector issued three (18.4\%) or four or more units $(6.4 \%)$ per transfusion event more often than the public sector (12.1\% and 3.6\%, respectively) (Table 2).

A total of 3899389 RBC units were issued for the period 2014 2018 (Table 3). The number of RBC units issued remained stable from 2014 through 2018, with the highest number of units issued in 2015. RBC units issued in the public sector remained stable over this period, while they increased year on year in the private sector, except for a slight decrease in 2018 compared with 2017 (294 834 v. 295 850). The public sector population (excluding the Western Cape) grew from 39.09 million in 2014 to 42.66 million in 2018, while the private sector population showed a gradual decrease from 8.02 million in 2014 to 7.72 million in $2018 .^{[8,20-23]}$ Per capita RBC utilisation increased year on year in the private sector, from 34.81/1 000 population in 2014 to $38.21 / 1000$ population in 2018, and decreased marginally in the public sector from $11.89 / 1000$ population in 2014 to $11.02 / 1000$ population in 2018 .

\section{Discussion}

Evidence to date on SA blood utilisation generally suggests that blood product usage is positively associated with HIV prevalence, especially where treatment is absent. ${ }^{[24,25]}$ Further afield in subSaharan Africa, evidence indicates that blood usage is generally dominated by a young female demographic, with malignancies and complications arising during or as a result of pregnancies noted as clear drivers of blood utilisation. ${ }^{[26]}$ Our study not only confirms these usage trends observed within sub-Saharan Africa in general, but also verifies the anecdotal evidence, i.e. markedly different RBC utilisation patterns between the public and private healthcare sectors in SA. RBC product recipients are decidedly different across sectors, not only in population characteristics but also in $\mathrm{RBC}$ product usage. The public sector in the SANBS operational zones, which serviced $\sim 74 \%$ of the SA population between 2014 and 2018, ${ }^{[23,27]}$ accounted for only $60.7 \%$ of RBC utilisation, with females of childbearing age (20 - 45 years) comprising the largest demographic over the entire study period. In contrast, the private sector recipients were generally older (median 54 years v. 33 years in the public sector), with an approximately even distribution between the sexes $(46.6 \%$ male to $53.4 \%$ female).

Blood utilisation in the SA public sector approximates that of other middle-income countries, which is generally associated with paediatric use (children aged $<5$ years ${ }^{[28]}$ ) or adverse events during pregnancy. ${ }^{[28,29]}$ In stark contrast, the private sector RBC utilisation patterns are comparable to those of high-income countries, with recipient age distribution skewed towards the older age ranges. ${ }^{[28]}$

The disparities in RBC utilisation are most keenly expressed in the mean 5-year per capita RBC utilisation difference between the public (11.6 units per 1000 population) and private (36.7 units per 1000 population) sectors for the period 2014 - 2018. The public sector

Table 1. Demographic characteristics of the 2356441 public and private sector red blood cell transfusion events, 2014 - 2019

\begin{tabular}{lll}
\hline Requisitions & \multicolumn{1}{c}{ Public sector } & Private sector \\
\hline Transfusion events, $n(\%)$ & $1553159(65.9)$ & $803282(34.1)$ \\
Age (years), median (IQR) & $33(22-49)$ & $54(37-68)$ \\
Gender, $n$ (\%) & & \\
$\quad$ Male & $520772(33.5)$ & $373942(46.6)$ \\
Female & $1028549(66.2)$ & $428829(53.4)$ \\
$\quad$ Unknown & $3838(0.3)$ & $511(0.06)$ \\
IQR = interquartile range. & &
\end{tabular}




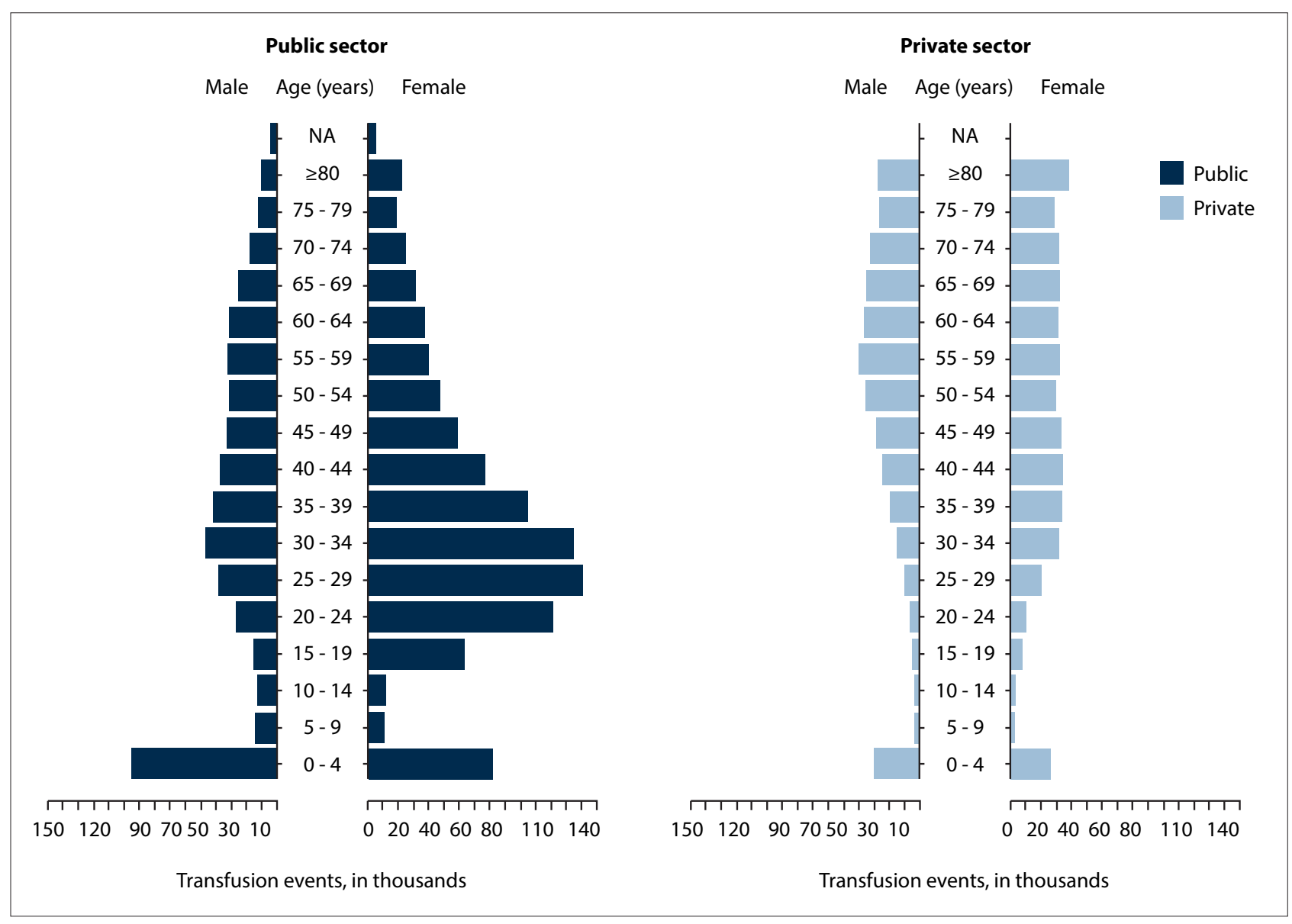

Fig. 1. Red blood cell transfusion events between 1 January 2014 and 31 March 2019, by gender and age in the public $(\mathrm{N}=1553159)$ and private $(\mathrm{N}=803282)$ sectors. (NA = ages not available. $)$

\begin{tabular}{lll}
\multicolumn{4}{l}{ Table 2. Trends in public and private sector red blood cell product units issued per transfusion event, 2014 - 2019 } \\
\hline Number of units per transfusion event & Public sector $(\boldsymbol{N = 1 5 5 3 ~ 1 5 9 ) , ~} \boldsymbol{n}$ (\%) & Private sector $(\boldsymbol{N}=\mathbf{8 0 3 ~ 2 8 2 ) , ~} \boldsymbol{n}(\%)$ \\
\hline 0 & $164507(10.6)$ & $48416(6)$ \\
1 & $558796(36)$ & $215670(26.8)$ \\
2 & $641217(41.3)$ & $391434(48.7)$ \\
3 & $133230(8.6)$ & $96265(12.0)$ \\
$\geq 4$ & $55409(3.57)$ & $51497(6.4)$
\end{tabular}

\begin{tabular}{|c|c|c|c|c|c|c|c|}
\hline Service date & Total units, $\boldsymbol{n}(\%)$ & Public sector, $\boldsymbol{n}(\%)$ & Private sector, $\boldsymbol{n}(\%)$ & $\begin{array}{l}\text { Public } \\
\text { population } \\
\text { estimates, }^{\dagger} \\
\text { millions }\end{array}$ & $\begin{array}{l}\text { Private } \\
\text { population } \\
\text { estimates, }{ }^{\dagger} \\
\text { millions }\end{array}$ & $\begin{array}{l}\text { Per capita } \\
\text { use in public } \\
\text { sector }\end{array}$ & $\begin{array}{l}\text { Per capita } \\
\text { use in private } \\
\text { sector }^{*}\end{array}$ \\
\hline 2014 & $762719(18.6)$ & 464769 (60.9) & 279279 (36.6) & 39.09 & 8.02 & 11.89 & 34.81 \\
\hline 2015 & $794322(19.3)$ & 489095 (61.6) & $286571(36.1)$ & 39.88 & 7.95 & 12.26 & 36.04 \\
\hline 2016 & $779393(19)$ & $470546(60.4)$ & $292397(37.5)$ & 40.37 & 7.93 & 11.66 & 36.88 \\
\hline 2017 & 783384 (19) & $472541(60.3)$ & $295850(37.8)$ & 41.80 & 7.87 & 11.31 & 37.59 \\
\hline 2018 & $779571(19)$ & $469948(60.3)$ & $294834(37.8)$ & 42.66 & 7.72 & 11.02 & 38.21 \\
\hline $2014-2018$ & 3899389 & 2366899 (60.7) & $1448931(37.2)$ & 203.78 & 39.49 & 11.62 & 36.69 \\
\hline
\end{tabular}


utilisation figures are less than the mean per capita RBC product utilisation over the same period for Namibia (13.5 units per 1000 population for $2014-2018),{ }^{[30-34]}$ an upper middle-income country. ${ }^{[35]}$ In contrast, the private sector was transfusing at rates exceeding those in many high-income countries, ${ }^{[28]}$ such as Australia (25.5 units per 1000 population) ${ }^{[36]}$ the UK (21.8 units per 1000 population $)^{[37,38]}$ and Switzerland (26.6 units per 1000 population), ${ }^{[39-41]}$ over the 1 -year period starting in 2017.

The underlying causes of these utilisation disparities are unclear, but contributing factors may include differences in: (i) disease profiles; (ii) transfusion prescribing practices among clinicians; and (iii) healthcare access. There is a paucity of information on differences in disease profiles, prescribing habits and access to healthcare between the public and private sectors in SA. The Global Burden of Disease Study $2019^{[42]}$ reported 5 of the top 10 causes of death and disability in SA to be related to communicable, maternal, neonatal, and nutritional disease, with HIV still the leading cause of death in the country. ${ }^{[2]}$ These have been shown to be driven by socioeconomic inequalities relating to employment status and geographical location, factors associated with accessing the public sector. ${ }^{[43]}$ There are numerous factors that may contribute to differences in transfusion prescribing habits, with a propensity towards liberal transfusion in the litigation-sensitive private sector and potentially more restrictive practices in the resource-limited public sector. A study by Barrett et al. ${ }^{[4]}$ on knowledge of transfusion among doctors at a tertiary academic (public sector) hospital noted poor knowledge of basic transfusion principles and infrequent training; the latter was also reported in an extensive review of transfusion medicine training in SA. ${ }^{[45]}$ Medical students at Universitas Academic Complex in Bloemfontein, for example, are only assigned 4 hours of lectures targeting transfusion medicine. ${ }^{[4]}$ Furthermore, the presence of hospital transfusion committees in many public sector hospitals may have provided greater oversight of transfusion prescribing practices compared with the private healthcare sector, which does not have any such committees in place (Dr Petro-Lize Wessels, personal communication, 7 January 2021). These regulatory bodies 'can provide important oversight of transfusion practice and dissemination of transfusion guidelines and monitor the implementation of new programs related to transfusion medicine in the hospital. ${ }^{[46]}$ The operation of these bodies - especially in the private healthcare sector - would allow for improved facilitation of transfusion practices aligned with prescribed guidelines, thereby curbing unnecessary and potentially harmful transfusions. Additionally, a programme of particular importance that these regulatory bodies would be essential to facilitate is patient blood management (PBM). PBM is defined as 'an evidence-based bundle of care to optimise medical and surgical patient outcomes by clinically managing and preserving a patient's blood. ${ }^{[47]}$ The implementation of PBM in Australia has been accredited for reducing per capita RBC use from 36.83 units per 1000 population ${ }^{[48]}$ in $2008 / 09$ to 25.5 units per 1000 population in 2017/18. ${ }^{[36]}$ Furthermore, PBM enabled a 50\% reduction in transfusions in an orthopaedic centre in Austria. ${ }^{[49]}$ The clinical guidelines for blood use in SA were last revised by blood product providers in 2014. ${ }^{[50]}$ Although PBM was incorporated into the latest version of these guidelines, a revision is required to incorporate the most recent evidence and guidelines regarding PBM.

In 2019, sub-Saharan Africa recorded both the highest under-5 and the highest maternal mortality worldwide, with 53\% and $68 \%$ of all worldwide under-5 and maternal deaths, respectively. ${ }^{[1,52]}$ Healthcare access is reported to be a factor contributing to these mortalities. Children aged $<5$ years residing in rural communities are at particularly high risk of death, possibly owing to delay in seeking the necessary treatment. ${ }^{[53]}$ Also, in terms of maternal healthcare, healthcare in sub-Saharan Africa is often associated with a lack of resources, contributing to the lack of access to such services. ${ }^{[54]}$ In better-resourced settings, anaemia is less prevalent among women (pregnant or not). ${ }^{[55]}$ Access is conceptualised by Peters et al. ${ }^{[56]}$ by merging the definitions into four main areas, namely geographical accessibility, financial accessibility, availability and acceptability. Although geographical and financial ability to access healthcare services are intuitive, availability and acceptability require further clarification. Within this framework, availability implies healthcare facilities having, among other things, the stock, expertise and staff to meet the requirements of those accessing these facilities. ${ }^{[56,57]}$ Furthermore, acceptability points towards the level of satisfaction with the healthcare facilities of those accessing these service providers. ${ }^{[57]}$

In SA, private healthcare facilities are mostly located in urban settings, ${ }^{\left[{ }^{58,59]}\right.}$ with the majority of the insured being prepared ${ }^{[60]}$ and able (owing to availability of private transport ${ }^{[60]}$ ) to access such facilities. The ability to afford private healthcare broadly suggests greater financial stability among those accessing the private sector. ${ }^{[59]}$ General acceptability within this healthcare sector is high $(97.6 \%),{ }^{[23]}$ and with a larger proportion of healthcare professionals and resources in comparison with the public sector, the private healthcare sector has high levels of availability ${ }^{[58]}$ The concept of access is more critical in the public sector, in view of the lower socioeconomic groups in SA shouldering the major burden of poor health. ${ }^{[5,61]}$ Generally, the public sector in SA is underfunded, particularly in relation to the proportion of the SA population it services. ${ }^{[58]}$ There are further intrasector disparities, with differences in resource designation between facilities. ${ }^{[58]}$ The public sector also has significant specialist resource limitations with, for example, 11.4 medical specialists per 100000 public sector population in 2013 compared with 86.5 per 100000 in the private sector. ${ }^{[62]}$ The public sector further suffers from shortages of equipment and medicinal stock, ${ }^{[63]}$ and has half the number of beds per individual compared with the private sector ${ }^{[58]}$ as well as variability in working hours between facilities, which all hinder availability. ${ }^{[63]}$ In terms of geographical accessibility, the lowest socioeconomic levels reported that transport costs influenced the time of access to services, resulting in delays in receiving necessary care. ${ }^{[60]}$ Furthermore, the urban location of tertiary and provincial hospitals is more beneficial to higher socioeconomic groups ${ }^{[63]}$ Finally, with regard to acceptability, a lower percentage of individuals (80.3\%) in comparison with the private sector $(97.6 \%)$ were satisfied in the public sector, ${ }^{[23]}$ with the delay time to service being of particular concern. ${ }^{[64]}$

\section{Conclusions}

Blood utilisation data for the two-tiered healthcare system of SA are lacking. The outcomes of this investigation aim to meet the need by providing sector-specific trends in utilisation, especially with a view to developing systems to implement NHI. Analysis indicates that the public healthcare sector is under-transfusing in terms of the proportion of the population accessing this healthcare sector. Comparatively, the private sector is transfusing at rates similar to high-income countries. The general disparities between the public and private healthcare sectors in SA could be a major factor contributing to the dramatic differences in the RBC utilisation patterns observed. Both healthcare sectors could benefit from greater priority being given to transfusion medicine training, with especial emphasis given to PBM and adherence to transfusion guidelines. The private healthcare sector requires more oversight in terms of hospital transfusion committees to improve management of blood transfusions. The results indicate that the public and private 
healthcare sectors in SA are essentially separate entities with unique blood utilisation drivers operating within each sector; nevertheless, they are interrelated systems, with both sectors, for example, dependent on the same pool of blood donors. Addressing the main factors driving the general disparities within each sector will enable greater equality in utilisation between the sectors.

\section{Declaration. None.}

Acknowledgements. The authors acknowledge and thank Dr Britta Lohrke, Senior Medical Officer, Blood Transfusion, Ministry of Health and Social Services, Namibia, for her provision of the Namibian RBC utilisation figures. They also thank the reviewer for the constructive remarks that contributed to development of the manuscript. This work is based on research supported by the Department of Science and Innovation and the National Research Foundation (NRF). Any opinion, finding, and conclusion or recommendation expressed in this material is that of the authors and the NRF does not accept any liability in this regard.

Author contributions. LB: conceptualisation, data curation, formal analysis, investigation, methodology, software, validation, visualisation, writing - original, writing - review and editing. KvdB: conceptualisation, supervision, methodology, project administration, writing - review and editing, resources. RS: conceptualisation, supervision, methodology, writing - review and editing. JRCP: conceptualisation, supervision, methodology, resources, funding acquisition, writing - review and editing. Funding. The SACEMA is supported by the NRF (LB and JRCP). KvdB and RS are employees of the SANBS, which also supported LB and JRCP. KvdB is supported in part by the US National Institutes of Health, Fogarty International Center (grant D43-TW010345).

Conflicts of interest. None.

1. Asante A, Price J, Hayen A, Jan S, Wiseman V. Equity in health care financing in low- and middle-income countries: A systematic review of evidence from studies using benefit and financing incidence analyses. PLoS ONE 2016;11(4):1-20. https://doi.org/10.1371/journal.pone.0152866

2. Mills A, Ataguba JE, Akazili J, et al. Equity in financing and use of health care in Ghana, South Africa, and Tanzania: Implications for paths to universal coverage. Lancet 2012;380(9837):126-133. https://doi. and Tanzania: Implications for paths

3. Burger R, Christian C. Access to health care in post-apartheid South Africa: Availability, affordability 3. Burger R, Christian C. Access to health care in post-apartheid South Africa: Availability, affordab
acceptability. Health Econ Policy Law 2020;15(1):43-55. https://doi.org/10.1017//1744133118000300

4. Vermeulen M, van den Berg K, Sykes W, et al. Health economic implications of testing blood donors in South Africa for HTLV 1 \& 2 infection. Vox Sang 2019;114(5):467-477. https://doi.org/10.1111/vox.12788 5. National Treasury, Republic of South Africa. Budget Review, 2018. http://www.treasury.gov.za/documents national\%20budget/2018/review/FullBR.pdf (accessed 9 December 2020).

6. Alaba OA, McIntyre D. What do we know about health service utilisation in South Africa? Dev South Aft 2012;29(5):704-724. https://doi.org/10.1080/0376835X.2012.730973

Ataguba JEO, McIntyre D. Who benefits from health services in South Africa? Health Econ Policy Law 2013;8(1):21-46. https://doi.org/10.1017/S1744133112000060

8. Statistics South Africa. General household survey 2015. Statistical release P0318. https://www.statssa.gov. za/publications/P0318/P03182015.pdf (accessed 9 January 2020).

9. Day C, Gray A, Ndlovu N. Health and related indicators 2018. In: South African Health Review 2018

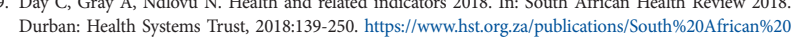
Durban: Health Systems Trust, 2018:139-250. https://www.hst.or

10. Marten R, McIntyre D, Travassos C, et al. An assessment of progress towards universal health coverage in Brazil, Russia, India, China, and South Africa (BRICS). Lancet 2014;384(9960):2164-2171. https://do org/10.1016/S0140-6736(14)60075-1

11. Department of Health, South Africa. National Health Insurance. http://www.health.gov.za/index.php/nhi\# (accessed 7 October 2019).

12. Statistics South Africa. Mid-year population estimates: 2018. Statistical release P0302. https://www.statssa. gov.za/publications/P0302/P03022018.pdf (accessed 7 January 2020).

13. Western Cape Blood Service. 2018 - 2019 Integrated Report. WCBS, 2019. https://www.wcbs.org.za (accessed 14 April 2020)

14. Vermeulen M, Sykes W, Coleman C, et al. The prevalence of human T-lymphotropic virus type 1 \& 2 (HTLV-1/2) in South African blood donors. Vox Sang 2019;114(5):451-458. https://doi.org/10.1111/ vox. 12778

15. Murphy MF, Yazer MH. Measuring and monitoring blood utilisation. Transfusion 2013;53(12):3025-3028. https://doi.org/10.1111/trf.12342

16. RStudio Team. RStudio: Integrated development environment for R, 2018. https://rstudio.com/

16. RStudio Team. RStudio: Integrated development environment for R, 2018. https://rstudio.com/

18. Groothuis-Oudshoorn K, van Buuren S. mice: Multivariate imputation by chained equations in R. J Stat Softw 2011;45(3):1-67. https://doi.org/10.18637/jss.v045.i03

19. Van Buuren S, Boshuizen HC, Knook DL. Multiple imputation of missing blood pressure covariates in survival analysis. Stat Med 1999;18(6):681-694. https://onlinelibrary.wiley.com/doi/10.1002/\%28SICI\%2910970258\%2819990330\%2918\%3A6\%3C681\%3A\%3AAID-SIM71\%3E3.0.CO\%3B2-R

20. Statistics South Africa. General household survey 2014. Statistical release P0318. http://www.statssa.gov.za/ publications/P0318/P03182014.pdf (accessed 9 January 2020).

21. Statistics South Africa. General household survey 2016. Statistical release P0318. https://www.statssa.gov. za/publications/P0318/P03182016.pdf (accessed 9 January 2020).
22. Statistics South Africa. General household survey 2017. Statistical release P0318. https://www.statssa.gov. za/publications/P0318/P03182017.pdf (accessed 9 January 2020).

23. Statistics South Africa. General household survey 2018. Statistical release P0318. https./wrww statssa.gov. za/publications/P0318/P03182018.pdf (accessed 9 January 2020).

24. Ntusi NBA, Sonderup MW. HIV/AIDS influences blood and blood product use at Groote Schuur Hospital, Cape Town. S Afr Med J 2011;101(7):463-466

25. Van den Berg K, Murphy EL, Pretorius L, Louw VJ. The impact of HIV-associated anaemia on the incidence of red blood cell transfusion: Implications for blood services in HIV endemic countries. Transfus Apher Sci 2014;51(3):10-18. https://doi.org/10.1016/.transci.2014.10.012

26. Butler EK, Hume H, Birungi I, et al. Blood utilisation at a national referral hospital in sub-Saharan Africa. Transfusion 2015;55(5):1058-1066. https://doi.org/10.1111/trf.13010

27. Statistics South Africa. Country projections by population group, sex and age (2002 - 2018). In: Mid-year population estimates, 2018. Statistical release P0302. http://www.statssa.gov.za/?page id $=1854 \& P P N=P 0302 \& S C H=7362$ (accessed 18 January 2019)

28. World Health Organization. Global status report on blood safety and availability 2016. Geneva: WHO, 2017. https://apps.who.int/iris/bitstream/handle/10665/254987/9789241565431-eng.pdf (accessed 17 August 2019).

29. Mafirakureva N, Khoza S, Hassall O, et al. Profiles of blood and blood component transfusion recipients in Zimbabwe. Blood Transfus 2015;13(4):600-609. https://www.ncbi.nlm.nih.gov/pmc/articles/PMC4624536/

30. Namibia Statistics Agency. Namibia 2011 census population projections 2011 to 2041. Windhoek: Namibia Statistics Agency, 2014. https://cms.my.na/assets/documents/p19dn4fhgp14t5ns24g4p6r1c401.pdf (accessed 19 March 2020)

31. Namibia Blood Transfusion Service. Namibia National Blood Programme 2015.

32. Namibia Blood Transfusion Service. Namibia National Blood Programme 2016

33. Namibia Blood Transfusion Service. Namibia National Blood Programme 2018.

34. Namibia Blood Transfusion Service. Haemovigilance data 2018

35. World Bank. World Bank list of economies. World Bank Group, 2020. https://datahelpdesk.worldbank. org/knowledgebase/articles/906519-world-bank-country-and-lending-groups (accessed 19 October 2020).

36. National Blood Authority Australia. Annual report 2017 - 18. Canberra: National Blood Authority Australia, 2018. https://www.blood.gov.au (accessed 30 August 2019).

37. Office for National Statistics, UK. National population projections: 2018-based. Office for National Statistics, 2019. https://www.ons.gove.uk (accessed 15 April 2020).

38. National Health Service, UK. NHS Blood and Transplant Annual Report and Accounts 2017/18. NHS, 2018. https://www.gov.uk/government/publications (accessed 15 April 2020).

39. Kucera J, Krummenacher A, eds. Switzerland's population 2017. Swiss Federal Statistics Office, 2017. hucera J, Krummenacher A, eds. Switzerland's population 2017. Swis
https://www.bfs.admin.ch/bfs/en/home.html (accessed 24 August 2021).

40. Krummenacher A, Rausa F, eds. Switzerland's population 2018. Swiss Federal Statistics Office, 2017. https:// Krummenacher A, Rausa F, eds. Switzerland's population 2018. Sw.
www.bfs.admin.ch/bfs/en/home.html (accessed 24 August 2021).

41. Swiss Transfusion SRC. Annual report 2017. Bern: Swiss Transfusion SRC, 2018. https://annualreport2017. transfusion.ch/key-figures/ (accessed 15 April 2020).

42. Vos T, Lim SS, Abbafati C, et al. Global burden of 369 diseases and injuries in 204 countries and territories, 1990 - 2019: A systematic analysis for the Global Burden of Disease Study 2019. Lancet 2020;396(10258):1204-1222. https://doi.org/10.1016/S0140-6736(20)30925-9

43. Omotoso KO, Koch SF. Assessing changes in social determinants of health inequalities in South Africa: A decomposition analysis. Int J Equity Health 2018;17(1):1-13. https://doi.org/10.1186/s12939-018-0885-y

44. Barrett C, Mphahlele K, Khunou I, et al. The knowledge of transfusion and related practices among doctors at Universitas Academic Complex, Bloemfontein, South Africa. Transfus Apher Sci 2020;59(3):102739. https://doi.org/10.1016/j.transci.2020.102739

45. Louw VJ, Nel MM, Hay JF. Factors affecting the current status of transfusion medicine education in South Africa. Transfus Apher Sci 2013;49(3):665-672. https://doi.org/10.1016/.jtransci.2013.05.003

46. Yazer MH, Lozano M, Fung M, et al. An international survey on the role of the hospital transfusion . Yazer MH, Lozano M, Fung M, et al. An international survey on the role of
committee. Transfusion 2017;57(5):1280-1287. https://doi.org/10.1111/trf.14033

47. International Foundation for Patient Blood Management. What is patient blood management? https:// International Foundation for Patient Blood Management. What is patient blood manage
www.ifpbm.org/knowledge/what-is-patient-blood-management (accessed 29 March 2021).

48. National Blood Authority Australia. Australian Haemovigilance Report 2010. Canberra: National Blood Authority Australia, 2010. https://www.blood.gov.au/system/files/documents/australian-haemovigilancereport-2010_0.pdf (accessed 30 March 2021)

49. Gombotz H, Rehak PH, Shander A, et al. The second Austrian benchmark study for blood use in elective surgery: Results and practice change. Transfusion 2014;54(1):2646-2657. https://doi.org/10.1111/trf.12687 5. South African National Blood Service, Western Cape Blood Service. Clinical guidelines for use of blood products in South Africa. 5th ed. SANBS/WCBS, 2014. https://www.wcbs.org.za (accessed 12 August 2019). UNICEF (United Nations Children's Fund). Under-five mortality. UNICEF, 2020. https://data.unicef.org/ topic/child-survival/under-five-mortality/ (accessed 9 February 2021).

52. UNICEF (United Nations Children's Fund). Maternal mortality. UNICEF, 2019. https://data.unicef.org/ topic/maternal-health/maternal-mortality/ (accessed 9 February 2021).

53. Rutherford ME, Dockerty JD, Jasseh M, et al. Access to health care and mortality of children under 5 years of age in The Gambia: A case-control study. Bull World Health Organ 2009;87(3):216-224. https://doi. of age in The Gambia: A c 5 .

54. Kyei-Nimakoh M, Carolan-Olah M, McCann TV. Access barriers to obstetric care at health facilities in subSaharan Africa - a systematic review. Syst Rev 2017;6(1):1-16. https://doi.org/10.1186/s13643-017-0503-x 55. Dominic A, Ogundipe A, Ogundipe O. Determinants of women access to healthcare services in subSaharan Africa. Open Public Health J 2020;12(1):504-514. https://doi.org/10.2174/1874944501912010504 56. Peters DH, Garg A, Bloom G, et al. Poverty and access to health care in developing countries. Ann N Y Acad Sci 2008;1136(1):161-171. https://doi.org/10.1196/annals.1425.011

57. McLaughlin CG, Wyszewianski L. Access to care: Remembering old lessons. Health Serv Res 2002;37(3):1441-1443. https://doi.org/10.1111/1475-6773.12171

58. Mcintyre D, Thiede M, Nkosi M, Mutyambizi V. A critical analysis of the current South African health system: SHIELD work package report. Cape Town: Health Economics Unit, University of Cape Town, and Centre for Health Policy, University of the Witwatersrand, 2007. http://web.uct.ac.za/depts/heu//SHIELD/ reports/SouthAfrical.pdf (accessed 21 February 2020).

59. Ataguba JE, McIntyre D. Paying for and receiving benefits from health services in South Africa: Is the health system equitable? Health Policy Plan 2012;27(Suppl 1):35-45. https://doi.org/10.1093/heapol/czs005

60. Harris B, Goudge J, Ataguba JE, et al. Inequities in access to health care in South Africa. J Public Health . Harris B, Goudge J, Ataguba JE, et al. Inequities in access to
Policy 2011;32:102-123. https://doi.org/10.1057/jphp.2011.35

61. Ataguba JE, Akazili J, McIntyre D. Socioeconomic-related health inequality in South Africa: Evidence from General Household Surveys. Int J Equity Health 2011;10(1):48. https://doi.org/10.1186/1475-9276-10-48

62. Econex. Identifying the determinants of and solutions to the shortage of doctors in South Africa: Is there a role for private sector in medical education? 2015. https://econex.co.za/wp-content/uploads/2015/08/ ECONEX_Doctor-shortages-and-training_FINAL1.pdf (accessed 17 November 2020)

63. Macha J, Harris B, Garshong B, et al. Factors influencing the burden of health care financing and the distribution of health care benefits in Ghana, Tanzania and South Africa. Health Policy Plan 2012;27(Suppl 1):46-54. https://doi.org/10.1093/heapol/czs024

64. Plaks S, Butler M. Access to public healthcare in South Africa. S Afr Actuar J 2012;12(1):129-164. https:// doi.org/10.4314/saaj.v12i1.5 